\title{
Organisational culture, environmental management control systems, environmental performance of Pakistani manufacturing industry
}

\begin{abstract}
Purpose: The purpose of this paper is to analyze the influence of organizational culture (OC) on a firm's environmental performance (EP) via the mediating variable of environmental management control systems (EMCS). Design/methodology/approach: Data were collected from 314 Pakistani manufacturing firms via the questionnaire survey, and the structural equation modeling was used to test the relationships. Findings: The stable and flexible values of OC affect the effectiveness of formal and informal EMCS. Informal EMCS mediates the relationship between flexible values and EP, whereas formal EMCS mediates the stable values and EP. Overall, the data reveal that the integration of environmental culture within an organization's culture and control systems leads to improve EP. Originality/value: The study is one of the first, to the author's knowledge, that links OC, EMCS, and EP in a developing economy, in this case Pakistan.
\end{abstract}

Keyword: Organizational culture; Environmental management control system; Environmental performance; Manufacturing industry; Contingency theory 